Journal of Engineering and Applied Sciences 14 (Special Issue 8): 10325-10330, 2019

ISSN: $1816-949 \mathrm{X}$

(C) Medwell Journals, 2019

\title{
Theoretical Study the Structure, Electronic and Spectra Properties for Nanotube Molecules by using DFT Method
}

\author{
Rajaa K. Mohammad \\ Department of Physics, College of Science, University of Kerbala, Karbala, Iraq
}

\begin{abstract}
DFT method has been carried out to studying the effects of $\mathrm{NH}_{3}, \mathrm{SO}_{2}, \mathrm{CO}_{2}, \mathrm{O}_{2}$ and $\mathrm{CH}_{3}$ on the nanotube $(2,2)$ using the B3LYP functional and the 3-21 G basis set, the optimization structure, properties such as Ionization potential (I), Electron affinity (E), Energy gap (Eg), thermal properties (Eth, CV and S), EPS and IR spectra. The CNTs (1 and 2) is semiconductor with Eg ranging from 0.98-0.90 eV. All properties are calculated by using Density Function (DFT) method with basis set 3-21 G.
\end{abstract}

$\underline{\text { Key words: DFT calculation, electronic properties, IR spectra, nanotube molecules, optimization, structure }}$

\section{INTRODUCTION}

Carbon Nanotubes (CNTs) represent a new group of materials with new application in technologies. Carbon nanotubes have several structures, differing in thickness, length and in the type of number of layers and helicity. $n$ and $\mathrm{m}$ denote the number of unit vectors along two directions (Odem et al.,1998). If $\mathrm{m}=0$, the nanotubes are called zigzag which is named for the pattern of hexagons as we move on circumference of the tube while if $n=m$ the nanotubes are called armchair or chirala which describes one of the two confirmers of cyclohexene of carbon atoms (Ganesh, 2013). Carbon nanotubes may have impact on semiconductor physics because of its the special electronic properties and very small size that are unique to carbon nano tubes. Because of the variety of possible helical geometries called as chirality, carbon nanotubes provide a family of structures with different chiralities and diameters (Saito et al., 1998).

Carbon Nanotubes (NTs) have been exhibit promising behavior for many application. One of the interesting facts is that their performance is completely dependent on the atomic geometrical organization. Ayala et al. (2010) many other materials as more results that are experimental became available and theoretical investigations, CNT was found to be not as perfect as it seems. These defects can significantly change the electrical, electronic, mechanical and thermal properties of CNTs (Meyyappan, 2005; Cahangirov et al., 2012). There are many approaches have been used to adjust the chemical doping electronic gap such as filling as an external stimulus and electric fields (Khoo and Louie, 2004; Ishigami et al., 2005; Kim et al., 2001; Zhi et al., 2005; Tang et al., 2005; Chen et al., 2007; Wei et al., 2010; Mickelson et al., 2003; Bando et al., 2001; Sirikumara et al., 2016).

For of seven different Carbon Nanotubes (CNTs) study the effect of physical properties and of surface chemistry carbon nanotubes on the adsorption of polycyclic aromaticin aqueous solutions (Al-Abboodi et al., 2017). Using DFT to study the electron properties, optical phonons and Raman spectroscopy of graphene: their relationship with carbon nanotubes (Charlier et al., 2007). Study the mechanical properties, chemical properties, optical properties and aplecation of carbon nanotubes (Varshney, 2014). Study the structure, symmetry, DOS physical and electronic properties and discussions related physical properties of carbon nanotubes also other electronic properties (Teng, 2010). Electrical, mechanical and thermal properties of carbon nanotube are study by using Chemical Vapor Deposition (CVD) (Kaushik and Majumder, 2015). The oretical and experimental analyses the topics covering the physical, structural, chemical electric properties and vibrational properties of carbon nanotubes (Suzuki, 2013).

\section{MATERIALS AND METHODS}

Computational approach: DFT calculations were performed using Gaussian 09 package (Frisch et al., 2009). The investigate the effect of $\mathrm{NH}_{3}, \mathrm{SO}_{2}, \mathrm{CO}_{2}, \mathrm{O}_{2}$ and $\mathrm{CH}_{3}$ on the nanotube $(2,2)$ have been performed with B3LYP/3-21G level in the gas phase. The B3LYP hybrid functional has shown to be highly successful for calculation the electronic properties such as I, E and Eg because the calculation of the energy interaction effects between electrons and exchange-correlation also shows most accurate results. Figure 1 shows the structure of (1-4) nanotube molecules at gas phase using DFT method with B3LYP. The energy $E^{\text {HOMO }}$ of the highest occupied orbital, energy $E^{\text {LUMO }}$ of the lowest unoccupied orbital. The Ionization potential (I) and Electron affinity (E) have been computed by Eq. 1 and 2 (Al-Yasari, 2017): 


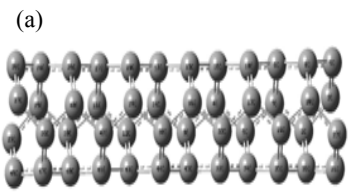

(d)

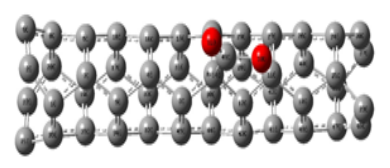

(b)

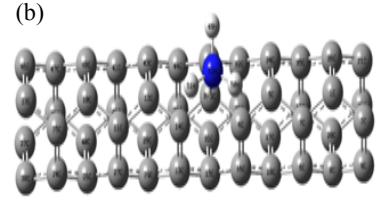

(e)
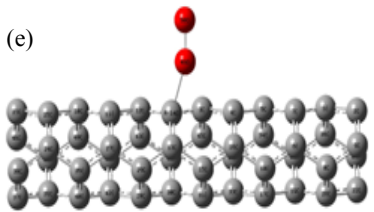
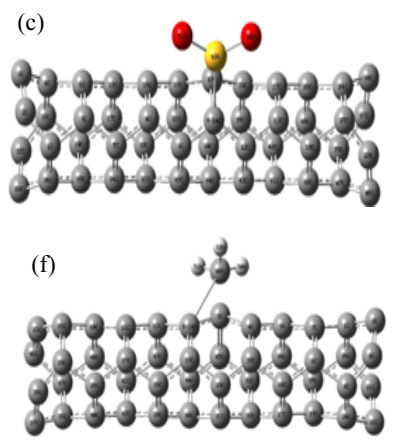

Fig. 1(a-f): The structures of (1-6) CNTS (2, 2) using DFT with B3LYP/3-21G bases set

$$
\begin{gathered}
\mathrm{I}=\mathrm{E}^{\text {HоMо }} \\
\mathrm{E}=\mathrm{E}^{\text {LUMO }} \\
\mathrm{E}_{\mathrm{g}}=\left(\mathrm{E}^{\mathrm{LUMO}}-\mathrm{E}^{\text {HOMO }}\right)
\end{gathered}
$$

The Fermi energy has been calculated by Eq. 3 (Al-Yasari, 2016):

$$
\left.E_{L}=-(I+E) / 2\right)
$$

Cohesive energy (Ecoh) can be calculated by Eq. 4 (Sahin et al., 2013):

$$
\mathrm{Ecoh}=(\mathrm{ETot} / \mathrm{n})-\text { Ecarbon }
$$

Where:

ETot : The total energy of the system

$\mathrm{n} \quad$ : The number of atoms in the system

Ecarbon : The calculated total energy of an isolated carbon atom $=1027.868 \mathrm{eV}$

\section{RESULTS AND DISCUSSION}

Electronic properties: All properties are computed by DFT/B3LYP 3-21G method for (Eq. 1-4) nanotube $(2,2)$ molecules. Table 1 shows the calculated values of HOMO and LUMO and electronic properties (I, E values (Eq. 1 and 2) while Ef values (Eq. 3) and EB values (Eq. 4). It is clear from Table 1 and Fig. 2-4 that the $\mathrm{NH}_{3}, \mathrm{SO}_{2}$ and $\mathrm{CO}_{2}$ gropes lead to decreasing the values of $\mathrm{HOMO}$ and increasing the vales of LOUMO. From this figure shows the electronic could distribution on along therings $\mathrm{C}-\mathrm{C}$ and the different parts of nanotube molecules, all molecules the HOMO shows a bonding character and LOUMO shows antibonding. The variation of LUMO and $\mathrm{HOMO}$ as the number of atoms of tube grows up in size.

While the values of $\mathrm{I}, \mathrm{Ef}, \mathrm{EB}$ and $\mathrm{Eg}$ are increasing while $\mathrm{E}$ are decreasing with the doping.
From Table 1 and Fig. 2 indicating that the CNTs (1 and 2) is semiconductor with Eg ranging from $0.98-0.90 \mathrm{eV}$.

Electrostatic Potential and density Surfaces (EPS): The electrostatic potential and density surfaces nanotube molecules 2-6 using DFT with 3-21G basis set and are shown in Fig. 3. The distribution of electrostatic potential and electron density surfaces depends on the type of dobing group atoms; also depend on negative and positive charges. From this figure the density distribution on nanotube molecules is homogenous while in nanotube molecules 2-6 distribution on the $\mathrm{NH}_{3}, \mathrm{SO}_{2}$, $\mathrm{CO}_{2}, \mathrm{O}_{2}$ and $\mathrm{CH}_{3}$. It is because these gropes have a high electronegativity, hence, it is engage charge toward them.

IR spectra: Figure 4 shows the IR spectra of nanotube molecules 1-6 using DFT method. The harmonic vibrational frequencies rotational constant, degree of freedom and vibration mod were calculated for study molecules by using B3LYP level with 3-21 G basis set. $\mathrm{NH}_{3}, \mathrm{SO}_{2}, \mathrm{CO}_{2}, \mathrm{O}_{2}$ and $\mathrm{CH}_{3}$ lead to new vibration mod such as $(\mathrm{N}-\mathrm{H}),(\mathrm{S}-\mathrm{O}),(\mathrm{C}-\mathrm{S})$ and $(\mathrm{C}-\mathrm{O}),\left(\mathrm{C}-\mathrm{CO}_{2}\right)$ is weak and increasing of vibrational modes. From this fiuger found the Nts (2-4) have high values of harmonic vibrational frequencies $(\mathrm{C}-\mathrm{C}),(\mathrm{C}=\mathrm{C})$ and $(\mathrm{C}-\mathrm{C}-\mathrm{C})$ compared pristine CNTs. According to the rule of $3 \mathrm{~N}-6$ where $\mathrm{N}$ is the number of atoms in nanotube molecules are calculated degree of freedom for CNTs from Table 2. Found the $\mathrm{NH}_{3}, \mathrm{SO}_{2}, \mathrm{CO}_{2}, \mathrm{O}_{2}$ and $\mathrm{CH}_{3}$ groups lead to increasing of rotational constant, degree of freedom.

Thermal properties: Table 3 shows the calculated values thermal properties (Eth, $\mathrm{CV}$ and $\mathrm{S}$ ) using DFT method with B3LYP. It is clear from this table that the $\mathrm{NH}_{3}, \mathrm{SO}_{2}$ and $\mathrm{CO}_{2}$ gropes lead to decreasing the values of Eth, $\mathrm{CV}$ and $\mathrm{S}$. The 3 has high $\mathrm{CV}$ and $\mathrm{S}$ while 2 has high values of Eth. Also the CNTs under study have high values of (Eth, CV and S) compered pristine CNTs. 
J. Eng. Applied Sci., 14 (Special Issue 8): 10325-10330, 2019

Table 1: HOMO, LUMO energies and electronic properties (I, E, Eg, Ef and EB) in (eV) units for nanotube molecules 1-6 using DFT with 3-21 G basis set

\begin{tabular}{|c|c|c|c|c|c|c|c|}
\hline Molecules & $\mathrm{HOMO}$ & LOUMO & I & $E$ & $\mathrm{Eg}$ & $\mathrm{Ef}$ & EB \\
\hline 1 & -5.34669 & -4.35703 & 5.346689 & 4.357025 & 0.989664 & -4.85186 & -1065.72 \\
\hline 2 & -4.71594 & -3.80954 & 4.715938 & 3.809540 & 0.906398 & -4.26274 & -1063.90 \\
\hline 3 & -5.99518 & -4.24356 & 5.995179 & 4.243555 & 1.751624 & -5.11937 & -1074.20 \\
\hline 4 & -5.67594 & -4.40437 & 5.675942 & 4.404372 & 1.271570 & -5.04016 & -1067.18 \\
\hline 5 & -5.51104 & -4.27104 & 5.511044 & 4.271039 & 1.240005 & -4.89104 & -1067.20 \\
\hline 6 & -5.81445 & -3.84818 & 5.814446 & 3.848180 & 1.966267 & -4.83131 & -1063.58 \\
\hline
\end{tabular}
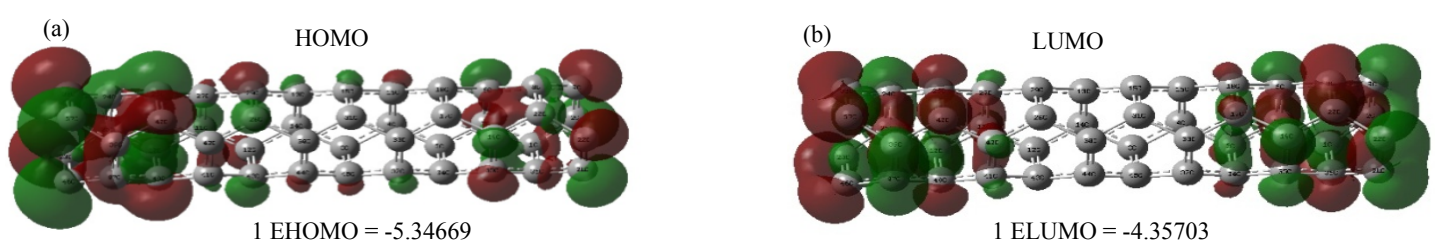

$\mathrm{Eg}=0.989664$

1 ELUMO $=-4.35703$
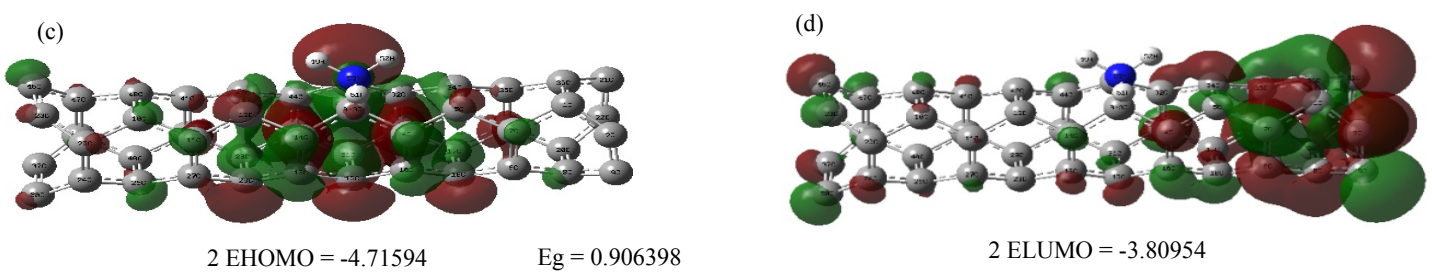

$2 \mathrm{ELUMO}=-3.80954$
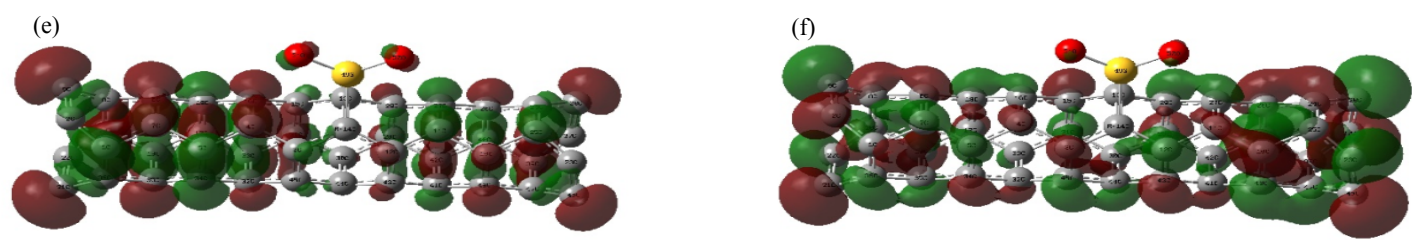

$3 \mathrm{EHOMO}=-5.99518$

$\mathrm{Eg}=1.751624$

3 ELUMO $=-4.24356$
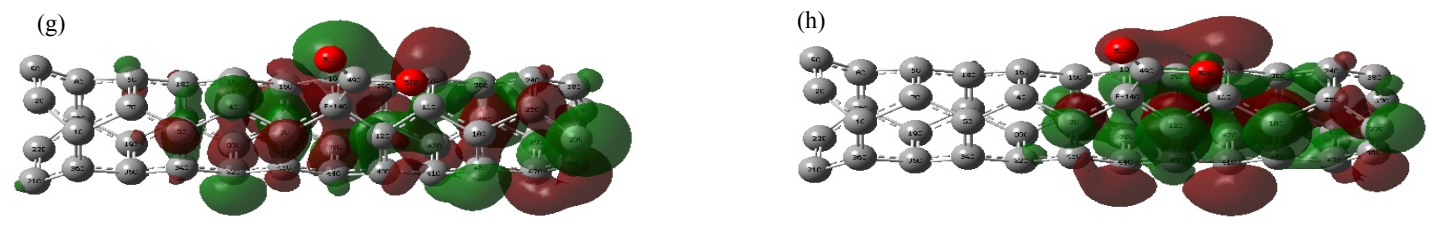

$4 \mathrm{EHOMO}=-5.67594$

$\mathrm{Eg}=1.27157 \quad 4 \mathrm{ELUMO}=-4.40437$
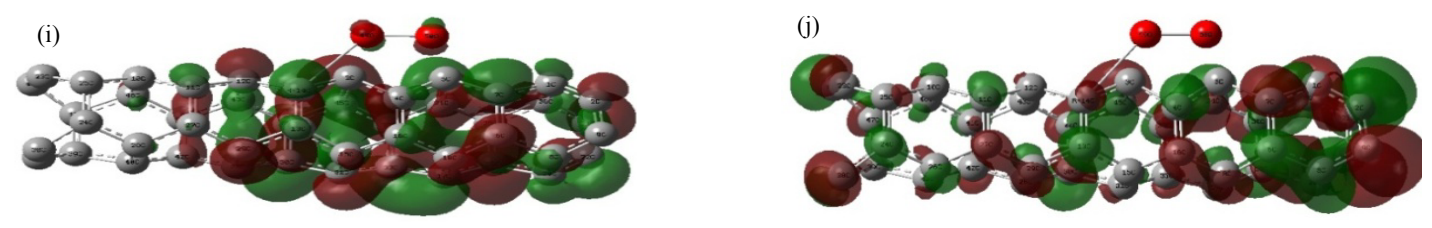

$5 \mathrm{EHOMO}=-5.51104$

$\mathrm{Eg}=1.240005$

5 ELUMO $=-4.27104$

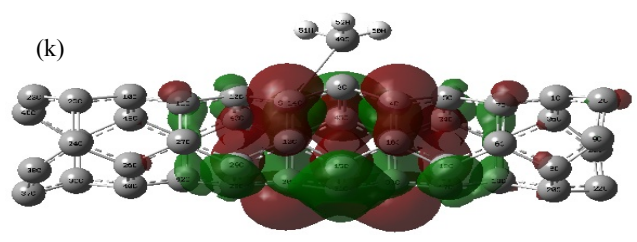

$6 \mathrm{EHOMO}=5.8144$

$\mathrm{Eg}=1.966267$

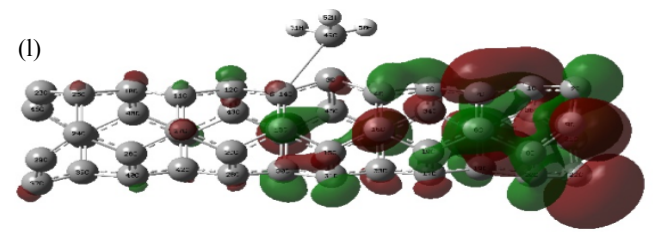

6 ELUMO $=3.84818$

Fig. 2(a-1): Shapes HOMO and LOUMO for nanotube molecules 1-6 using DFT with 3-21G basis set 
(a)

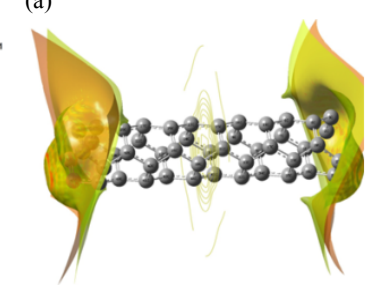

(d)

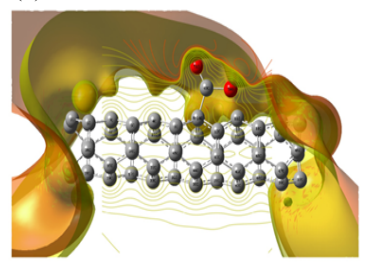

(b)

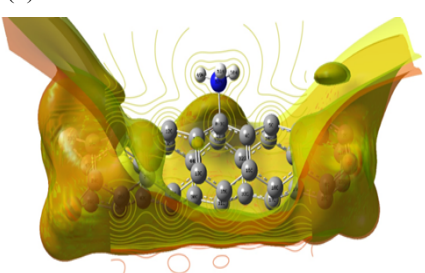

(e)

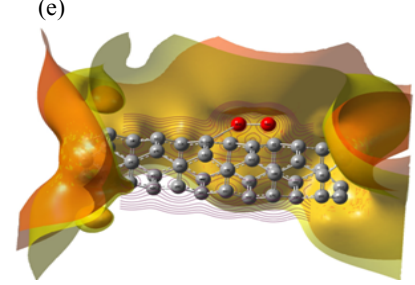

(c)

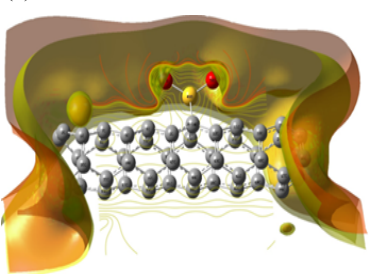

(f)

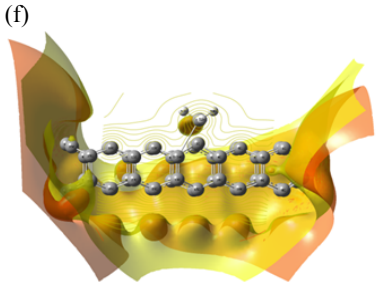

Fig. 3(a-f): The electrostatic potential and density surfaces for nanotube molecules 1-6 using DFT with 3-21G basis set

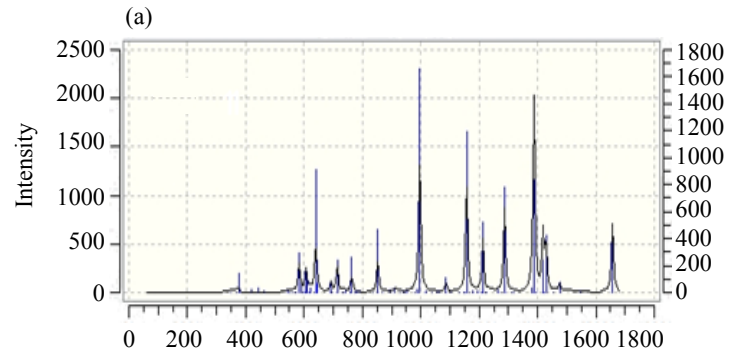

(c)
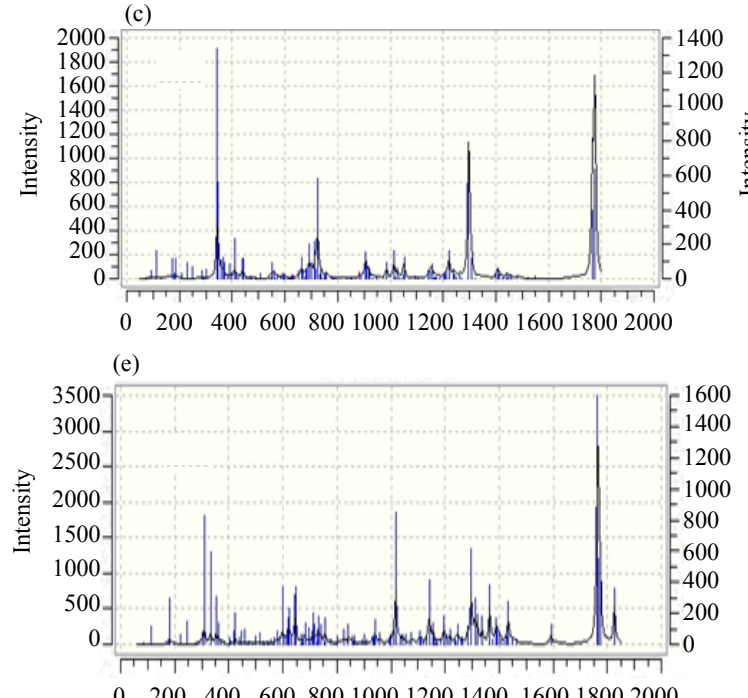

$0 \quad 200400600800100012001400160018002000$

Frequency $\left(\mathrm{cm}^{-1}\right)$
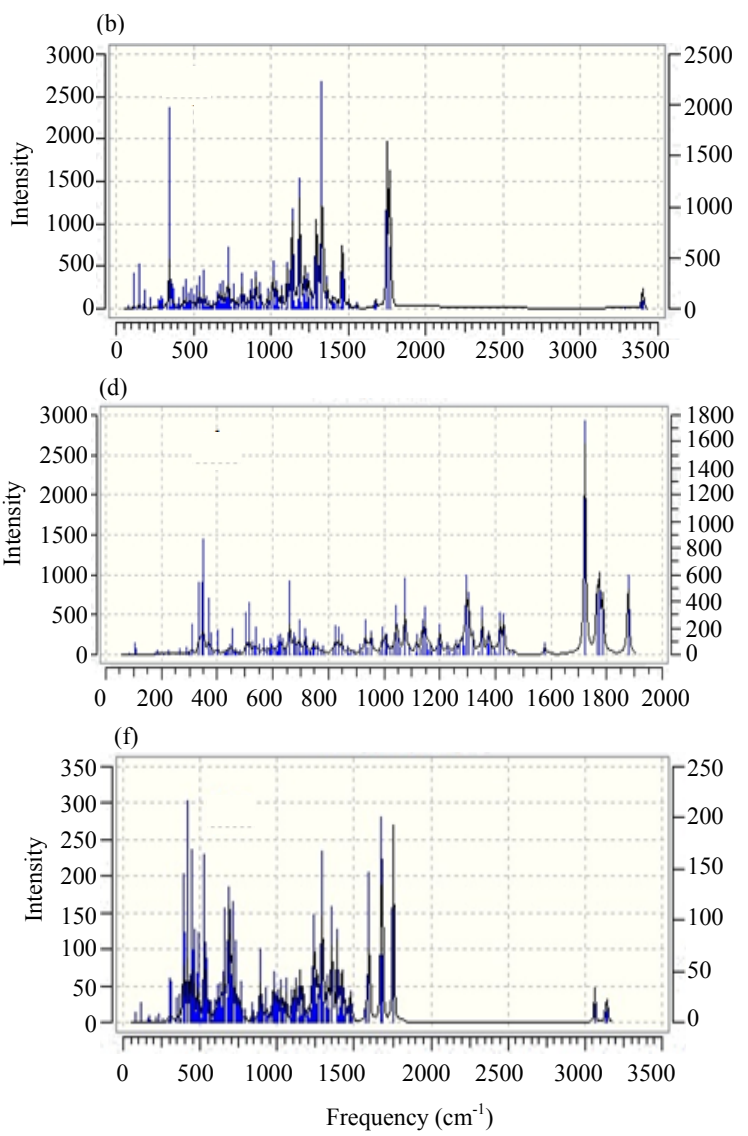

Fig. 4(a-f): Shapes IR spectra for nanotube molecules 1-6 using DFT with 3-21G; IR spectrum

Table 2: Vibration frequencies rotational constant in (Gl), degree. of freedom and vibration mod for nanotube molecules 1-6 using DFT with $3-21 \mathrm{G}$ basis set

\begin{tabular}{lllcc}
\hline Molecules & Vibration mode & Frequency $\left(\mathrm{cm}^{-1}\right)$ & Degree of freedom & Rotational constant \\
\hline 1 & C $=$ C, C-C stretching & $1657.2,1165.27$ & 35 & 0.4254143 \\
2 & N-H stretching C = C, C-C stretching & $3404.48 ; 1529.04,1330.16$ & 150 & 0.3666001 \\
\hline
\end{tabular}




\begin{tabular}{|c|c|c|c|c|}
\hline & $\mathrm{N}-\mathrm{H}_{3}$ rocking, waging & $1674.46,1128.69$ & & \\
\hline \multirow[t]{2}{*}{3} & S-O stretching $\mathrm{C}=\mathrm{C}, \mathrm{C}-\mathrm{C}$ stretching & $1052.55 ; 1459.62,1322.13$ & 147 & 0.2628798 \\
\hline & C-S set reaching S-O sesoring & $1012.9,416.082$ & & \\
\hline 4 & $\begin{array}{l}\mathrm{C}-\mathrm{O} \text { stretching } \mathrm{C}=\mathrm{C}, \mathrm{C}-\mathrm{C} \text { stretching } \\
\mathrm{C}-\mathrm{CO}_{2} \text { rocking }\end{array}$ & $\begin{array}{l}1877.54 ; 1786.04,1318.98 \\
482.308\end{array}$ & 147 & 0.2947358 \\
\hline 5 & $\begin{array}{l}\mathrm{C}-\mathrm{O}_{2} \text { stretching } \mathrm{C}=\mathrm{C}, \mathrm{C}-\mathrm{C} \text { stretching } \\
\mathrm{O}-\mathrm{O} \text { waging, stretching }\end{array}$ & $\begin{array}{l}309.533 ; 1826.27,1374.8 \\
5482.308 ; 931.77,801.587\end{array}$ & 144 & 0.3354019 \\
\hline 6 & $\begin{array}{l}\mathrm{C}=\mathrm{H} \text { stretching } \mathrm{C}=\mathrm{C}, \mathrm{C}-\mathrm{C} \text { stretching } \\
\mathrm{C}-\mathrm{H}_{3} \text { bending, rocking, waging }\end{array}$ & $\begin{array}{l}3145.8 ; 1755.05,1598.3 \\
3064.45,1060.77,1153.89\end{array}$ & 150 & 0.3663494 \\
\hline
\end{tabular}

Table 3: Eth, CV and $\mathrm{S}$ in $\mathrm{Kcal} / \mathrm{mol}$ and $\mathrm{cal} / \mathrm{mol}-\mathrm{Kelvin}$ units for nanotube molecules 1-4 using DFT with 3-21 G basis set

\begin{tabular}{|c|c|c|c|}
\hline Molecules & Eth & $\mathrm{CV}$ & $\mathrm{S}$ \\
\hline 1 & 174.194 & 105.283 & 141.199 \\
\hline 2 & 209.194 & 114.894 & 152.055 \\
\hline 3 & 190.578 & 119.497 & 160.388 \\
\hline 4 & 191.863 & 116.922 & 153.508 \\
\hline 5 & 187.121 & 114.918 & 150.911 \\
\hline 6 & 205.670 & 116.460 & 154.183 \\
\hline
\end{tabular}

\section{CONCLUSION}

In this study found the $\mathrm{NH}_{3}, \mathrm{SO}_{2}$ and $\mathrm{CO}_{2}$ gropes lead to decreasing the values of $\mathrm{HOMO}$ and increasing the vales of LOUMO. From this figure shows the electronic could distribution on along the rings $\mathrm{C}-\mathrm{C}$ and the different parts of nanotube molecules the CNTs (1 and 2) is semiconductor with Eg ranging from $0.98-0.90 \mathrm{eV}$ and lead to decreasing the values of Eth, $\mathrm{CV}$ and $\mathrm{S}$. The 3 molecule has high $\mathrm{CV}$ and $\mathrm{S}, \mathrm{NH}_{3}, \mathrm{SO}_{2}$ and $\mathrm{CO}_{2}$ lead to increasing of vibrational modes such as $(\mathrm{N}-\mathrm{H})$ at $3404.48 \mathrm{~cm}^{-1}$ for 2 molecule, (S-O) at $1052.55 \mathrm{~cm}^{-1}$ an (C-S) at 1012.9 set reaching $\mathrm{cm}^{-1}$ and (C-O) at $1877.54 \mathrm{~cm}^{-1}$ and $\left(\mathrm{C}-\mathrm{CO}_{2}\right)$ rocking $482.308 \mathrm{~cm}^{-1}$. The density distribution on nanotube molecules is homogenous while in nanotube molecules 2-6 distribution on the $\mathrm{NH}_{3}, \mathrm{SO}_{2} \mathrm{CO}_{2}, \mathrm{O}_{2}$ and $\mathrm{CH}_{3}$. It is because these gropes have a high electronegativity, therefore, it is attract charge toward them.

\section{REFERENCES}

Al-Abboodi, M.H., F.N. Ajeel and A.M. Khudhair, 2017. Influence of Oxygen impurities on the electronic properties of graphene nanoflakes. Phys. E. Low Dimensional Syst. Nanostruct., 88: 1-5.

Al-Yasari, R.K., 2016. Studies of the substitution effects on the electronic properties for biphenyl and derivative molecules by using DFT method. Chem. J. Moldova, 11: 61-68.

Al-Yasari, R.K., 2017. Analysis of molecular structures and spectroscopic properties of thiophene molecules. J. Chem. Pharm. Sci., 10: 940-944.

Ayala, P., R. Arenal, A. Loiseau, A. Rubio and T. Pichler, 2010. The physical and chemical properties of heteronanotubes. Rev. Mod. Phys., 82: 1843-1885.

Bando, Y., K. Ogawa and D. Golberg, 2001. Insulating nanocables: Invar Fe-Ni alloy nanorods inside BN nanotubes. Chem. Phys. Lett., 347: 349-354.
Cahangirov, S., C. Ataca, M. Topsakal, H. Sahin and S. Ciraci, 2012. Frictional figures of merit for single layered nanostructures. Phys. Rev. Lett., 108: 126103-1-126103-5.

Charlier, J.C., P.C. Eklund, J. Zhu and A.C. Ferrari, 2007. Electron and Phonon Properties of Graphene: Their Relationship with Carbon Nanotubes. In: Carbon Nanotubes: Advanced Topics in the Synthesis, Structure, Properties and Applications, Jorio, A., G. Dresselhaus and M.S. Dresselhaus (Eds.). Springer, Berlin, Germany, ISBN: 978-3-540-72864-1, pp: 673-709.

Chen, H., Y. Chen, C.P. Li, H. Zhang and J.S. Williams et al., 2007. Eu-doped Boron nitride nanotubes as a nanometer-sized visible-light source. Adv. Mater., 19: 1845-1848.

Frisch, M.J.E.A., G.W. Trucks, H.B. Schlegel, G.E. Scuseria and M.A. Robb et al., 2009. Gaussian 09, revision a. 02. Gaussian Inc., Wallingford, Connecticut, USA.

Ganesh, E.N., 2013. Single walled and multi walled Carbon nanotube structure, synthesis and applications. Intl. J. Innovative Technol. Exploring Eng., 2: 311-320.

Ishigami, M., J.D. Sau, S. Aloni, M.L. Cohen and A. Zettl, 2005. Observation of the giant Stark effect in Boron-nitride nanotubes. Phys. Rev. Lett., 94: 056804-1-056804-4.

Kaushik, B.K. and M.K. Majumder, 2015. Carbon Nanotube based VLSI Interconnects: Analysis and Design. Springer, New Delhi, India, ISBN:978-81-322-2046-6, Pages: 86.

Khoo, K.H. and S.G. Louie, 2004. Tuning the electronic properties of Boron nitride nanotubes with transverse electric fields: A giant dc Stark effect. Phys. Rev. B., 69: 201401-201401.

Kim, Y.H., K.J. Chang and S.G. Louie, 2001. Electronic structure of radially deformed $\mathrm{BN}$ and $\mathrm{BC} 3$ nanotubes. Phys. Rev. B., 63: 205408-205408.

Meyyappan, M., 2005. Carbon Nanotubes: Science and Applications. CRC Press, Boca Raton, Florida, USA., ISBN:9780849321115, Pages: 289.

Mickelson, W., S. Aloni, W.Q. Han, J. Cumings and A. Zettl, 2003. Packing C60 in Boron nitride nanotubes. Sci., 300: 467-469. 
Odom, T.W., J.L. Huang, P. Kim and C.M. Lieber, 1998. Atomic structure and electronic properties of single-walled Carbon nanotubes. Nat., 391: 62-64.

Sahin, H., J. Sivek, S. Li, B. Partoens and F.M. Peeters, 2013. Stone-Wales defects in Silicene: Formation, stability and reactivity of defect sites. Phys. Rev. B., 88: 045434-045434.

Saito, R., G. Dresselhaus and M.S. Dresselhaus, 1998. Physical Properties of Carbon Nanotubes. 2nd Edn., Imperial College Press, London, England, UK., ISBN:9781860940934, Pages: 259.

Sirikumara, H.I., E. Putz, M. Al-Abboodi and T. Jayasekera, 2016. Symmetry induced semimetal-semiconductor transition in doped graphene. Sci. Rep., 6: 1-8.

Suzuki, S., 2013. Physical and Chemical Properties of Carbon Nanotubes. IntechOpen, London, England, UK., ISBN:978-953-51-1002-6, Pages: 416.
Tang, C., Y. Bando, Y. Huang, S. Yue and C. Gu et al., 2005. Fluorination and electrical conductivity of BN nanotubes. J. Am. Chem. Soc., 127: 6552-6553.

Teng, A., 2010. Physical properties of Carbon nanotubes. MSc Thesis, Department of Physics, University of Tennesseem, Knoxville, Tennessee.

Varshney, K., 2014. Carbon nanotubes: A review on synthesis, properties and applications. Intl. J. Eng. Res. Gen. Sci., 2: 660-677.

Wei, X., M.S. Wang, Y. Bando and D. Golberg, 2010. Post-synthesis carbon doping of individual multiwalled boron nitride nanotubes via electron-beam irradiation. J. Am. Chem. Soc., 132: 13592-13593.

Zhi, C., Y. Bando, C. Tang, S. Honda and K. Sato et al., 2005. Covalent functionalization: Towards soluble multiwalled Boron nitride nanotubes. Angew. Chem. Intl. Ed., 44: 7932-7935. 